\title{
Association of Chlamydia Pneumoniae Infection With Atherosclerotic Plaque Formation
}

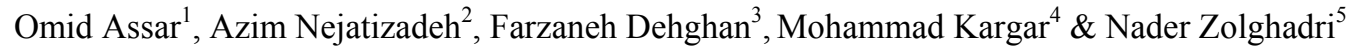 \\ ${ }^{1}$ Alborz University of Medical Sciences, Karaj, Iran \\ ${ }^{2}$ Cardiovascular Research Center, Hormozgan University of Medical Sciences, BandarAbbas, Iran \\ ${ }^{3}$ Molecular Medicine Research Center, Hormozgan University of Medical Sciences, BandarAbbas, Iran \\ ${ }^{4}$ Department of Microbiology, Islamic Azad University, Jahrom branch, Jahrom, Iran \\ ${ }^{5}$ Department of Mathematics, Islamic Azad University, Sama College, BandarAbbas, Iran \\ Correspondence: Farzaneh Dehghan, Molecular Medicine Research Center, Hormozgan University of Medical \\ Sciences, BandarAbbas, Iran. Tel: 98-917-168-5935. Fax: 98-763-335-4939. E-mail: \\ dehghanfarzaneh@ymail.com
}

Received: May 17, 2015 Accepted: July 31, 2015 Online Published: September 28, 2015

doi:10.5539/gjhs.v8n4p260 URL: http://dx.doi.org/10.5539/gjhs.v8n4p260

\begin{abstract}
Atherosclerosis is a complex multifactorial disorder. Studies show that infectious microbial agents may play an important role in the development of atherosclerosis; however, these findings are conflicting. This study investigated the presence of Chlamydia pneumoniae DNA in atherosclerotic plaques of patients suffering from coronary artery disease. In a cross-sectional study, 85 patients (43 females and 42 males with mean age of $61 \pm 9.5$, range $42-82$ years) referred for coronary artery bypass grafting (CABG) and thoracic biopsy as the control groups were enrolled for this study. Standard questionnaires, including demographic and clinical evaluation were administered. Obtained specimens were processed and then nested polymerase chain reaction with primers for Pst 1 fragment was carried out to detect Chlamydia pneumoniae DNA. Statistical analysis was done using the SPSS software. Of note, in 25 out of the 85 patients $(29.4 \%)$, C. pneumoniae was detected within atherosclerotic plaques, whereas, 5 out of the 85 thoracic biopsy $(5.9 \%)$ were positive for the presence of the mentioned bacteria in internal thoracic artery. There was a statistically significant association between atherosclerotic plaque (study group) and thoracic biopsy (control group) in terms of C. pneumoniae positivity $(\mathrm{P}=0.0001)$. The findings of this study support the hypothesis that $C$. pneumoniae is associated with atherosclerosis.
\end{abstract}

Keyword: Chlamydia pneumoniae, atherosclerosis, nested polymerase chain reaction

\section{Introduction}

Inflammation plays an essential role in atherosclerotic plaque formation. Obviously, infections are proposed as strong determinants of atherosclerosis (Ross, 1999). It is evident that, infectious agents such as C. pneumoniae have the ability to initiate and develop a chronic inflammation as an infectious state (Kol, Sukhova, Lichtman, \& Libby, 1998). Atherosclerosis is the leading cause of coronary vascular disease (CVD) (Izadi et al., 2013) which is a big challenge for the health status of humans (Jha \& Mittal, 2013). Evidence indicates that morbidity and mortality of cardiovascular disease worldwide would be intensified from $28.9 \%$ in 1999 to $36.3 \%$ in 2020 (Selami, Suat, Ozcan, Serhat, \& Turan, 2013). Development of athermanous plaques in coronary vessels of human seems to be multifactorial (Kwon et al., 2004). Although hypertension, hypercholesterolemia, smoking, diabetes mellitus, obesity are considered as the conventional risk factors for atherosclerosis. However, they could, in part, determine the pathogenesis of the disease (Kwon et al., 2004; Hedayat et al., 2009; Njamnshi et al., 2006; Al-Khatib \& Al-Alawneh, 2013; Jha, Srivastava, Divya, Prasad, \& Mittal, 2009).

The possible role of some organisms such as C. pneumoniae, Helicobacter pylori, mycoplasma pneumoniae and herpes virus family has been suggested in atherosclerotic disease (D.Pietro, Filardo, D. Santis, \& Sessa, 2013; Rupp, Kothe, Mueller, Maass, \& Dalhoff, 2003; Kaplan et al., 2006; Rupp \& Maass, 2004). Among these organisms $C$. pneumoniae received the most attention, as it could be treated by antibiotic therapy (Sadeghian et al., 2013; Woods, Walker, McPherson, \& Pincus, 2007; Zibaeenezhad, Amanat, Alborzi, \& Obudi, 2005; Cherian, 
A.Bharati, Bobryshev, Nayar, \& J. Ragavendra, 2006; Smieja, Mahony, Petrich, Boman, \& Chernesky, 2002). In contrast, the causal role of $C$. pneumoniae infection remains to be elucidated (Loehe et al., 2002). C. pneumoniae is an obligatory intracellular bacterium that affects the majority of global adults and children during life (Peeling \& Brunham, 1996). For the first time, in 1988, the association of this bacterium with coronary artery disease (CAD) was found (Saikku et al., 1988). Animal investigations were shown association between C. pneumoniae and development of atherosclerosis (Fong et al., 1997). Among the controversial studies, there is no consensus on the pathogenicity of $C$. pneumoniae in the initiation and formation of (Izadi et al., 2013) atherosclerotic plaque in humans.

C. pneumoniae infection and atherosclerotic heart disease are relatively high in Iran (Zibaeenezhad et al., 2005; Rostami et al., 2013; Shirani et al., 2006). It has been estimated that by 2030, more than 23 million people will die from cardiovascular disorders in the world (Jha \& Mittal, 2013). In this regard, a study to investigate the presence of C. pneumoniae in atherosclerotic plaque of Iranian patients using polymerase chain reaction (PCR) was conducted. Furthermore, this study determined the correlation between the bacterium and atherosclerotic risk factors, in patients undergoing coronary artery bypass graft (CABG). It seems that the obtained results could help in elucidating the pathogenesis of atherosclerosis.

\section{Methods and Materials}

\subsection{Study Population}

In this cross-sectional study, 85 patients referred for coronary artery bypass grafting (CABG) at Jorjani Heart Center Of Shahid Mohammadi Hospital in Bandarabbas, from November 2010 to June 2011 were enrolled. None of the patients had previously undergone $\mathrm{CABG}$ or percutaneous coronary intervention. A standard questionnaire was used to collect demographic and clinical characteristics of patients which comprised of age, gender, obesity, body mass index (BMI) $\geq 30 \mathrm{~kg} / \mathrm{m}^{2}$, smoking status (ex-smoker or current smoker), hypertension (reported history of hypertension or blood pressure $\geq 140 \mathrm{mmHg}$ ), hypercholesterolemia (total cholesterol $>200 \mathrm{mg} / \mathrm{dl}$ and LDL $>130 \mathrm{mg} / \mathrm{dl}$ ), diabetes mellitus (fasting blood sugar level $>126 \mathrm{mg} / \mathrm{dl}$ or reported history of diabetes) and family history of coronary artery disease (Salarifar, Kazemeini,\& Haji Zeinali, 2007) and complete history of prior medical conditions.

The ethics committee of the cardiovascular research center of Hormozgan University of medical sciences reviewed and approved the study. Written informed consents were obtained from the patients prior to specimen collection. Specimens from aortic atherosclerotic plaques (study group) and the same number was obtained from the internal mammary artery (control group) with no atherosclerotic degeneration were obtained during operation for coronary artery bypass grafting. All specimens were transported in Tris-EDTA buffer and kept at $-80^{\circ} \mathrm{C}$ for DNA extraction and C. pneumoniae detection.

\subsection{Molecular Analyses}

DNA extraction from $25 \mathrm{mg}$ of each specimen was performed using the Cinna Pure DNA extraction Kit (cinna gen, Iran), according to the manufacturer's instructions. The extracted DNA was qualified by spectrophotometric method. Specific inner and outer primers reported by Reszka (Table 1) were used for amplification of $C$. pneumoniae Pst1 fragment by nested PCR (Reszka, Jegier, Wasowicz, \& Lelonek, 2008). The reactions were carried out in $25 \mu \mathrm{l}$ of the reaction mixture containing $2 \mu \mathrm{l}$ of DNA, $2.5 \mu \mathrm{l}$ buffer $10 \mathrm{x}, 0.75 \mu 1 \mathrm{MgCl}_{2} 50 \mathrm{mM}, 0.4$ $\mu \mathrm{l}$ dNTPs $10 \mathrm{mM}, 0.5 \mu \mathrm{l}$ of each outer primer at $10 \mathrm{pmol} / \mu \mathrm{l}$ and $0.25 \mu \mathrm{l}$ of super Taq DNA polymerase $(5 \mathrm{U} / \mu \mathrm{l})$. DNA was amplified during 40 cycles with an initial denaturation of $3 \mathrm{~min}$ at $95^{\circ} \mathrm{C}$ and a final extension of $5 \mathrm{~min}$ at $72^{\circ} \mathrm{C}$. The cycling program consisted of $30 \mathrm{~s}$ denaturation at $95^{\circ} \mathrm{C}, 45 \mathrm{~s}$ annealing at $60^{\circ} \mathrm{C}$ and $30 \mathrm{~s}$ extension at $72^{\circ} \mathrm{C}$. The reaction mixture of the second round PCR was identical to the first round, except that $1 \mu \mathrm{l}$ of the first round product and inner primer (CPN1, CPN2) were used. Also, the PCR conditions were the same for the first round, but only 35 cycles were used. Negative control (distilled water) and positive control (genome of $C$. pneumoniae, vircell, Spanish) were run with all reactions. The products were visualized by electrophoresis on a $2 \%$ agarose gel with an appropriate molecular size marker (100bp DNA ladder, Gen Fanavaran, Iran) and examined under UV light. 
Table 1. PCR primer for amplification of C.pneumonia Pst1 fragment

\begin{tabular}{lll}
\hline Primer name & Primer sequence $\left(5^{\prime}-3^{\prime}\right)$ & Size $(\mathrm{bp})$ \\
\hline CP1 & TTATTCACCGTCCTACAGCAGAAA & 404 \\
CP2 & GGGGGTTCAGGGATCATTTGT & \\
CPN1 & TTACGAAACGGCATTACAACGGCTAGAAATCAAT & 214 \\
CPN2 & TATGGCATATCCGCTTCGGGAACGAT & \\
\hline
\end{tabular}

\subsection{Data Analysis}

Statistical analysis was carried out by means of SPSS version 19 software program to compare categorical variables. Fisher's Exact Test (2-sided P-value) was used. A P-value of less than 0.05 was considered statistically significant.

\section{Results}

A total of 85 patients including 43 (50.6\%) females and 42 (49.4\%) males with a mean age of 61 years (range of 42-82) participated in the study. C. pneumoniae DNA (Figure 1) was positive in $29.4 \%$ (25 out of 85) of atherosclerotic plaques, whereas in samples of internal mammary artery biopsies, $5.9 \%$ (5 out of 85 ) were detected. Simultaneously, 3 patients were positive for $C$. pneumoniae in both atherosclerotic plaques and internal mammary artery biopsies. These results revealed a statistically significant association between $C$. pneumoniae DNA positivity in atherosclerotic plaques and atherosclerosis $(\mathrm{P}=0.0001)$. Nine (9) out of the 85 patients had no atherosclerotic risk factor but other patients showed 1 to 5 risk factors. Demographic and clinical features in patient with C. pneumoniae positive and negative DNA are summarized in Table 2. There was no statistically significant difference between C. pneumoniae positive DNA and the atherosclerotic risk factors.

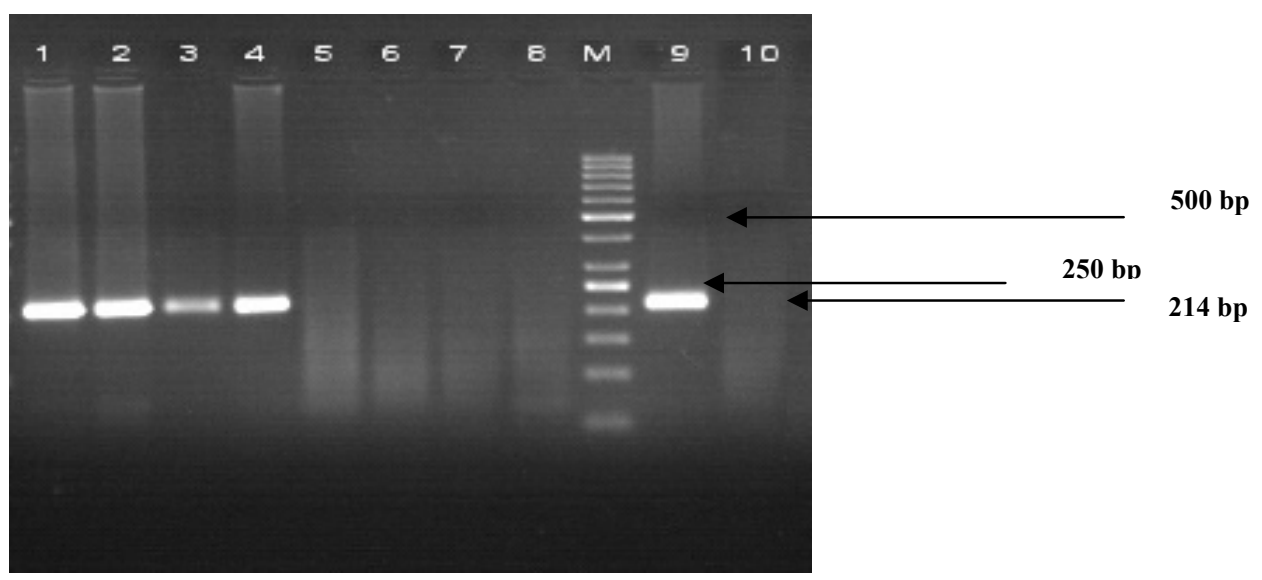

Figure 1. PCR product of C.pneumoniae was electrophoresed in 2\% Agarose gel. Lane1-4 positive sample, 5-8 negative sample, $\mathrm{M}$, size marker, 9 , Positive control, 10, negative control

Table 2. Clinical Characteristics of Patient with respect to C. pneumoniae DNA Positivity

\begin{tabular}{|c|c|c|c|c|c|}
\hline \multirow{3}{*}{ Parameters } & \multicolumn{2}{|c|}{ C.pneumoniae in Aorta } & \multicolumn{3}{|c|}{ C.pneumoniae in Mammary artery biopsy } \\
\hline & Positive & Negative & Positive & Negative & P-value \\
\hline & $\mathrm{n}=25$ & $\mathrm{n}=60$ & $\mathrm{n}=5$ & $\mathrm{n}=80$ & \\
\hline Mean Age & $60.3 \pm 9.7$ & $61.7 \pm 9.5$ & $63.6 \pm 5.2$ & $61.1 \pm 9.7$ & 0.12 \\
\hline Female & $14(\% 56)$ & $29(\% 48.3)$ & $4(\% 80)$ & $39(\% 48.8)$ & 0.55 \\
\hline Male & $11(\% 44)$ & $31(\% 51.7)$ & $1(\% 20)$ & $40(\% 51.2)$ & \\
\hline Smoking Habit & $9(\% 36)$ & $27(\% 45)$ & $3(\% 60)$ & $33(\% 41.2)$ & 0.44 \\
\hline Diabetes & $10(\% 40)$ & $23(\% 38.3)$ & $4(\% 80)$ & $33(\% 41.2)$ & 0.05 \\
\hline
\end{tabular}




\begin{tabular}{llllll}
\hline Hypertension & $9(\% 36)$ & $31(\% 51.7)$ & $5(\% 100)$ & $35(\% 43.8)$ & 0.62 \\
Hypercholesterolemia & $5(\% 36)$ & $31(\% 51.7)$ & $5(\% 100)$ & $35(\% 43.8)$ & 0.86 \\
Obesity & $2(\% 8)$ & $2(\% 3.3)$ & $0(\% 0)$ & $4(\% 5)$ & 0.65 \\
Family History & $8(\% 32)$ & $11(\% 18.3)$ & $3(\% 60)$ & $16(\% 20)$ & 0.17 \\
\hline
\end{tabular}

\section{Discussion}

Chronic infections and atherosclerosis showed unknown associations for years (Izadi et al., 2013. Izadi et al., 2014). C. pneumoniae is an intracellular obligatory microorganism (Wohlschlaeger, Wimmer, Nogler, Haberl, \& Weis, 2005), and for the first time, Shore et al described the presence of $C$. pneumoniae in atheroma plaques, by the PCR method (Shore, Kuo,\& Patton, 1992),. It has also been indicated as a possible cause of atherosclerosis (Joshi, Khandelwal, Joshi, \& Gupta, 2013). Subsequently, researchers looked for a possible association between C. pneumoniae and atherosclerosis, because of the high prevalence of $C$. pneumoniae infection in the general population (Izadi et al., 2013). In this study, C. pneumoniae was detected with a relative frequency of $29.4 \%$ in atherosclerotic plaque and $5.9 \%$ in biopsies from the internal mammary artery and a significant difference was observed between C. pneumoniae and atherosclerosis.

The findings of this study correspond to studies conducted by Sessa et al. (2007), Lui et al. (2006), Petyaev et al. (2010), Chatzidimitriou et al. (Chatzidimitriou, Melidou, Gioula, Exindari, \& Georgios, 2009), Kaklikkaya et al. (Kaklikkaya et al., 2006) and Wang et al. (Wang et al., 2007),whereas contrasting findings such as that of Bayram et al. (Bayram, Erdoğan, Ekşi, \& Yamak, 2011), Know et al. (2004), Reszka et al. (Reszka, Jegier, Wasowicz, \& Lelonek, 2008) and Iriz et al. (2008) succeeded to detect C. pneumoniae DNA in 30, 1.6, 27.5 and $15.1 \%$ of their studied samples respectively. However, these studies could not find any association between $C$. pneumoniae and atherosclerosis. Moreover, the studies of Tremolada et al. (2011), Bishara et al. (2003), Satpathy et al. (Satpathy, Bhan, Sharma, \& Kar, 2008), Sodeck et al. (2004), West et al. (2009), Campbell et al. (Campell \& Kuo, 2004), Apfalter et al. (2004), Watt et al. (Watt, Aesch, Lanotte, Tranquart, \& Quentin, 2003) and Bossone et al. (2008) did not isolate C. pneumoniae DNA from atherosclerotic specimens by PCR. Furthermore, findings of the same studies in Iran with the association between C. pneumoniae infection and atherosclerosis are contrasting, where some studies revealed an association between $C$. pneumoniae infection and atherosclerosis (Rostami et al., 2013; Bahrmand et al., 2004; Dabiri et al., 2009) while, others could not (Sadeghian et al., 2013; Zibaeenezhad et al., 2005; Pooria et al., 2009; Hosseinian, Habibzadeh, Ahari, \& Mokhtarpoor, 2007).

Disparity in the prevalence of C. pneumoniae could be due to selection of samples (Jha \& Mittal, 2013), differences in the size of tested samples (Bishara et al., 2003) and using various methods such as serology, PCR, Immunocytochemistry, electron microscopy and culture (Forbes, Sahm,\& Weissfeld., 2002) at diverse periods (Ieven \& Hoyman, 2005).

Also, this study did not observe any significant difference in the atherosclerotic risk factors between the two patient groups in terms of $C$. pneumoniae PCR positive and C. pneumoniae PCR negative. In addition, the prevalence of these factors was lower in the C. pneumoniae positive group. Interestingly, 4 out of the 29 patients with positive PCR had none of the atherosclerotic risk factors while the others had one to five risk factors. It appears unlikely that infection seems to be the only or main cause of atherosclerosis (Dabiri et al., 2009).

The results of this study support the studies of Farsak et al from Turkey (Farsak et al., 2000) and Loehe et al from Germany (Loehe et al., 2002) but were different to that of Iran. Dabiri et al. in their study found high prevalence of $C$. pneumoniae infection among smokers than in non-smokers (Campell \& Kuo, 2004). Furthermore, Eslami et al. and Hedayat et al. reported higher total Cholesterol in the PCR positive group (Pooria et al., 2009; Fallah et al., 2000). One possible explanation for this discrepancy is that, the number of male patients with higher incidence of heart disease and risk factors were more, while there was an approximately equal number of a male and female patient, likely influencing the results of the risk factors.

However, several limitations were encountered in the present study. This study could not consider the $C$. pneumoniae strains because the association of this chronic infection with the risk of atherosclerosis is likely limited to specific pathogenic strain. Furthermore, lack of serological information of the studied patients is another limitation of this study.

\section{Conclusion}

The results of this study support the hypothesis that C. pneumoniae is associated with atherosclerosis. Hence, efforts for eradication of $C$. pneumoniae infection are needed to determine whether its eradication decreases the 
incidence of this major life-threatening disease or not.

\section{Acknowledgements}

The authors express special thanks to the research and technology department, Hormozgan University of Medical Sciences, Hormozgan, Iran. Special thanks also go to the participants and hospital staff for their kind cooperation and help.

\section{Conflict of Interest}

The authors declare that there is no conflict of interests regarding the publication of this paper.

\section{References}

Al-Khatib, A. J. M., \& Al-Alawneh, M. (2013). Exploring the relationship between the infection of C.pneumoniae and coronary artery disease. European Scientific Journal, 9, 195-213.

Apfalter, P., Barousch, W., Nehr, M., Willinger, B., Rotter, M., \& Hirschl, A. M. (2004). No evidence of involvement of Chlamydia pneumoniae in severe cerebrovascular atherosclerosis by means of quantitative real-time polymerase chain reaction. Stroke, 35, 2024-208. http://dx.doi.org/ 10.1161/01.STR.0000137765.64705.d8.

Bahrmand, A. R., Bahadori, M., Hossaini, A., Velayati, A. A., Aghabozorgy, S., Shakoor, A., \& Bakayev, V. V. (2004). Chlamydia pneumoniae DNA is more frequent in advanced than in mild atherosclerosislesions. Scand J Infect Dis, 36, 119-123.

Bayram, A., Erdoğan, M. B., Ekşi, F., \& Yamak, B. (2011). Demonstration of Chlamydophila pneumoniae, Mycoplasma pneumoniae, Cytomegalovirus, and Epstein-Barr virus in atherosclerotic coronary arteries, nonrheumatic calcific aortic and rheumatic stenotic mitral valves by polymerase chain reaction. Anadolu Kardiyol Derg, 11, 237-243. http://dx.doi.org/ 237-243. 10.5152/akd.2011.057

Bishara, J., Pitlik, S., Kazakov, A., Sahar, G., Haddad, M., Vojdani ., ... Samra, Z. (2003). Failure to detect Chlamydia pneumoniae by cell culture and polymerase chain reaction in major arteries of 93 patients with atherosclerosis. Eur J Clin Microbiol, 22, 300-302. http://dx.doi.org/10.1007/s10096-003-0912-8

Bossone, E., Trimarchi, S., Esposito, G., Aliberti, S., Citro, R., Allegra, L., \& Blasi, F. (2008). Chlamydia pneumoniae and acute aortic syndrome: a call for a multi-institutional study. Monaldi Arch Chest Dis, 70, $68-670$.

Campell, L. A., \& Kuo, C. C. (2004). Chlamydia pneumoniae-an infectious risk factor for atherosclerosis? Nat Rev Microbial, 2, 23-32. http://dx.doi.org/10.1038/nrmicro796

Chatzidimitriou, D., Melidou, A., Gioula, G., Exindari, M., \&Georgios,T. (2009). Detection of Chlamydia neumoniae (Chlamydophila pneumoniae) DNA in atherosclerotic plaques and its molecular analysis in northern Greece. aristotle University Medical J, 3, 45-51.

Cherian, M. S., A. Bharati, S., Bobryshev, Y., Nayar, S., \& J. Ragavendra, B. (2006). Is Chlamydia pneumoniae associated with calcification in coronary atherosclerosis? Ind J of Thoracic and Cardiovascular Surgery, 22, 126-131.

D.Pietro, M., Filardo, S., D. Santis, F., \& Sessa, R. (2013). Chlamydia pneumoniae Infection in Atherosclerotic Lesion Development through Oxidative Stress: A Brief Overview. Int J Mol Sci, 14, 15105-15120. http://dx.doi.org/10.3390/ijms140715105

Dabiri, H., Rezadehbashi, M., Badami, N., Aghanouri, R., Ahmadi, H., Khoramizadeh, M. R., ... Zali, M. R. (2009). Detection of Chlamydia pneumoniae in atherosclerotic plaques of patients in Tehran, Iran. Jpn JInfect Dis, 62, 195-197.

Fallah, F., Eslami, G., Bootorabi, M., Kazemi, B., Goudarzi, H., \& Mazaheri, E. (2006). The isolation of Chlamydia pneumoniae in atherosclerosis patients in Iran by PCR method. Gene Ther Mol Biol, 10, 109-112.

Farsak, B., Yildirir, A., Akyön, Y., Pinar, A., Oç, M., Böke, E., Kes, S., \& Tokgözoğlu, L. (2000). Detection of Chlamydia pneumoniae and Helicobacter pylori DNA in human atherosclerotic plaques by PCR. J Clin Microbiol, 38, 4408-4411.

Fong, I. W., Chiu, B., Viira, E., Fong, M. W., Jang, D., \& Mahony, J. (1997). Rabbit model for Chlamydia pneumoniae infection. J Clin Microbiol, 35, 48-52.

Forbes, B. A., Sahm, D. F., \& Weissfeld, A. S. (2002). Bailey and Scott's Diagnostic Microbiology (11th ed., pp. 
578-579). Mosby Elsevier.

Hedayat, D. K., Jebeli, M., Mandegar, M. H., Bagheri, J., Nabavi, S. A., Eghtesadi, A. P., ... Abbasi, A. (2009). The association between Chlamydia pneumoniae DNA in arherosclerotic plaque and major risk factors in patients ndergoing coronary artery bypass grafting. Kardiol Pol, 67, 981-986.

Hosseinian, A., Habibzadeh, S. H., Ahari, S. S., \& Mokhtarpoor, A. (2007). The study of previous contact with Chlamydia pneumoniae in patients with myocardial infarction. $J$ Ardabil University Med Sci Health Services, 7, 35-40. [In persian].

Ieven, M. M., \& Hoyman, V. Y. (2005). Involvement of Chlamydia pneumoniae in Atherosclerosis: More Evidence for Lack of Evidence. $J$ Clin Microbiol, 43, 19-24. http://dx.doi.org/ 10.1128/JCM.43.1.19-24.2005.

Iriz, E., Cirak, M. Y., Engin, E. D., Zor, M. H., Erer, D., Ozdogan, M. E., Turet, S., \& Yener, A. (2008). Detection of Helicobacter pylori DNA in Aortic and Left Internal Mammary Artery Biopsies, Texas. Heart Institute, 35, 130-135.

Izadi, M., Fazel, M., Akrami, M., Saadat, S. H., Pishgoo, B., Nasseri, M. H., ... Taheri, S.(2013). Chlamydia pneumoniae in the Atherosclerotic Plaques of Coronary Artery Disease Patients, Acta Medica Iranica, 51, 864-870.

Izadi, M., Zamani, M.M., Sabetkish, N., Abolhassani, H., Saadat, S.H., Taheri, S.,\& Dabiri, H. (2014). The Probable Role of Cytomegalovirus in Acute Myocardial Infarction. Jundishapur J Microbiol, 7(3), e9253. http://dx.doi.org/10.5812/jjm.9253

Jha, H. C., Srivastava, P., Divya, A., Prasad, J., \& Mittal, A. (2009). Prevalence of Chlamydophila pneumoniae is higher in aorta and coronary artery than in carotid artery of coronary artery disease patients. Apmis, 117, 905-911. http://dx.doi.org/ 10.1111/j.1600-0463.2009.02553.x

Jha, H. C., \& Mittal, A. (2013). Impact of viral and bacterial infections in coronary artery disease patients. World J Transl Med, 2, 49-55. http://dx.doi.org/ 10.5528/wjtm.v2.i3.49

Joshi, R., Khandelwal, B., Joshi, D., \& Gupta, O. P. (2013). Chlamydophila Pneumoniae Infection and Cardiovascular Disease. North American Journal of Medical Sciences, 5, 169-181. http://dx.doi.org/ 10.4103/1947-2714.109178.

Kaklikkaya, I., Kaklikkaya, N., Buruk, K., Pulathan, Z., Koramaz, I., Aydin ,F.,... Ozcan ,F. (2006). Investigation of Chlamydia pneumoniae DNA, chlamydial lipopolisaccharide antigens, and Helicobacter pylori DNA in atherosclerotic plaques of patients with aortoiliac occlusive disease. Cardiovasc Pathol, 15, 105-109. http://dx.doi.org/10.1016/j.carpath.2005.12.001.

Kaplan, M., Yavuz, S. S., Cinar, B., Koksal, V., Kut, M. S., Yapici, F., ... Demirtas, M. M. (2006). Detection of Chlamydia pneumoniae and Helicobacter pylori in atherosclerotic plaques of carotid artery by polymerase chain reaction. Int J Infect Dis, 10, 116-123. http://dx.doi.org/ 10.1016/j.ijid.2004.10.008.

Kol, A., Sukhova, G. K., Lichtman, A. H., \&Libby, P. (1998). Chlamydial heat shock protein 60 localizes in human atheroma and regulates macrophage tumor necrosis factor-alpha and matrix metalloproteinase expression. Circulation, 98, 300-307. http://dx.doi.org/ 10.1161/01.CIR.98.4.300 .

Kwon, T. W., Kim, D. K., Ye, J. S., Lee, W. J., Moon, M. S., Joo, C. H., ... Kim, Y. K. (2004). Detection of Enterovirus, Cytomegalovirus, and Chlamydia pneumoniae in theromas. J Microbiol, 42, 299-304.

Liu, R., Moroi, M., Yamamoto, M., Kubota, T., Ono, T., Funatsu, A., ... Hara, H. (2006). Presence and severity of Chlamydia pneumoniae and Cytomegalovirus infection in coronary plaques are associated with acute coronary syndromes. Int Heart J, 47, 511-519. http://dx.doi.org/ 10.1536/ihj.47.511

Loehe, F., Bittmanm, I., weibach, Ch., Lauterjung, L., Schildberg, F. W., \& Heiss, M. M. (2002). Chlamydia pneumoniae in Atherosclerotic Lesions of Patients Undergoing Vascular Surgery. Ann Vasc Surg, 16, 467-473. http://dx.doi.org/ 10.1007/s10016-001-0178-5

Njamnshi, A. K., Blackett, K. N., Mbuagbaw, J. N., Gumedze, F., Gupta, S., \& Wiysonge, C. S. (2006). Chronic Chlamydia pneumoniae Infection and Stroke in Cameroon a case-control study, Stroke, 37, 796-799. http://dx.doi.org/ 10.1161/01.STR.0000204223.04182.4a

Peeling, R. W., \& Brunham, R. C. (1996). Chlamydiae as pathogens: new species and new issues. Emerg Infect Dis, 2, 307-319. 
Petvaev, I. M., Zigangirova, N. A., Petyaev, A. M., Pashko, U. P., Didenko, L. V., Morgunova, E. U., \& Bashmakov, Y. K. (2010). Isolation of Chlamydia pneumoniae from serum samples of the patients with acute coronary syndrome. Int J Med Sci, 7, 181-190.

Pooria, A., Maasoomi, M., Rafiee, E., Sabzi, F., Rezaee, M., Hossainzadegan, H., ... MozafarI, F. (2009). Relationship between Chlamydia pneumoniae and Helicobacter Pylori with atherosclerosis. Yafteh, 10, 3-11. [In Persian]

Reszka, E., Jegier, B., Wasowicz, W., \& Lelonek, M. (2008). Detection of infectious agents by polymerase chain reaction in human aortic wall. Cardiovascular Pathology, 17, 297-302. http://dx.doi.org/10.1016/j.carpath.2007.11.002.

Ross, R. (1999). Atherosclerosis-an inflammatory disease. $N$ Engl $J$ Med, 340, 115-126. http://dx.doi.org/10.1056/NEJM199901143400207.

Rostami Nejad, M., Lahmi, F., Nazemalhosseini, H., Mojarad, E., Godarzi, H., Ahmadi, H., \& Dabiri, H. (2013). Chlamydia pneumoniae infection in patients with atherosclerotic plaques. J Army Univ Med Sci, 11, 175-179. [In Persian]

Rupp, J., Kothe, H., Mueller, A., Maass, M., \&Dalhoff, K. (2003). Imbalanced secretion of IL-1beta and IL-1RA in Chlamydia pneumoniae infected mononuclear cells from COPD patients. Eur Respir, 22, 274-279.

Rupp, J., \& Maass, M. (2004). Interaction of host and microbes in the atherosclerotic plaques. Int Congr., 430-433. http://dx.doi.org/10.1016/S0531-5131(03)01857-0 .

Sadeghian, M. H. Tabatabaee Yazdi, S. A., Keramati, M. R., Ghazvini, K., Rezai, A. R., Heidari, N., ... Shaghayegh, G. (2013). Is there any relationship between Chlamydophila pneumoniae and coronary atherosclerosis among Iranians? Niger Med J, 54, 40-44. http://dx.doi.org/ 10.4103/0300-1652.108894.

Saikku, P., Leinonen, M., Mattila, K., Ekman, M. R., Nieminen, M. S., Makela, P. H., ... Valtonen, V. (1988). Serological evidence of an association of a novel Chlamydia, TWAR, with chronic coronary heart disease and acute myocardial infarction. Lancet, 2, 983-986. http://dx.doi.org/10.1016/S0140-6736(88)90741-6.

Salarifar, M., Kazemeini, S. M., \&Haji Zeinali, A. M. (2007). Prevalence of Coronary Artery Disease and related risk factors in first degree relatives of patients with premature CAD. Tehran Heart Center. Tehran University Medical Journal, 65, 49-54. [In Persian]

Satpathy, G., Bhan, A., Sharma, A., \& Kar, U. K. (2008). Detection of Chlamydophila pneumoniae (Chlamydia pneumoniae) in endarteroctomy specimens of coronary heart diseases patients. Indian $\mathrm{J}$ Med Res, 128, 658-662.

Selami, G., Suat, C. Z., Ozcan, G., Serhat, H., \& Turan, E. (2013). The Role of Chlamydia pneumoniae in the Atherosclerotic Process of Patients under 50 Years of Age Who Underwent Coronary Artery Bypass Graft Surgery. World Journal of Cardiovascular Surgery, 3, 146-151. http://dx.doi.org/10.4236/wjcs.2013.35030

Sessa, R., Di Pietro, M., Schiavoni, G., Petrucca, A., Cipriani, P., Zagaglia, C., ... Del Piano, M. (2007). Measurement of Chlamydia pneumoniae bacterial load in peripheral blood mononuclear cells may be helpful to assess the state of chlamydial infection in patients with carotid atherosclerotic disease. Atherosclerosis, 195, 224-230. http://dx.doi.org/10.1016/j.atherosclerosis.2007.04.052

Shirani, S., Boroumand, M. A., Abbasi, S. H., Maghsoodi, N., Shakiba, M., Karimi, A., Davoodi, S., \& Esfandbod, M. (2006). Preoperative carotid artery screening in patients undergoing coronary artery bypass graft surgery. Arch Med Res, 37, 987-990. http://dx.doi.org/10.1016/j.arcmed.2006.06.001

Shore, A., Kuo, C.C., \& Patton, D. L. (1992). Detection of Chlamydia pneumoniae in coronary arterial fatty streaks and atheromatous plaques. Afr Med J, 82, 158-161.

Smieja, M., Mahony, J., Petrich, A., Boman, J., \& Chernesky, M. (2002). Association of circulating Chlamydia pneumoniae DNA with cardiovascular disease: a systematic review. BMC infect dis, 2, 21-29. http://dx.doi.org/ 10.1186/1471-2334-2-21.

Sodeck, G., Domanovits, H., Khanakah, G., Schillinger, M., Thalmann, M., Bayegan, K., Hoelzenbein, T., ... Stanek, G. (2004). The role of Chlamydia pneumoniae in human aortic disease-A Hypothesis revisited. Eur J Vasc Endovasc Surg, 28, 547-552. http://dx.doi.org/10.1016/j.ejvs.2004.07.019

Tremolada, S., Delbue, S., Ferraresso, M., Carloni, C., Elia, F., Larocca, S., Bortolani, E., \& Ferrante, P. (2011). Search for genomic sequences of microbial agents in atherosclerotic plaques. Int $J$ Im munopathol Pharmacol, 24, 243-246. http://dx.doi.org/ 10.1177/039463201102400130. 
Wang, S. S., Tondella, M. L., Bajpai, A., Mathew, A. G., Mehranpour, P., Li, W., Kacharava, A. G., .. Zafari, A. M. (2007). Circulating Chlamydia pneumoniae DNA and advanced coronary artery disease. Int J Cardiol, 118, 215-219. http://dx.doi.org/ 10.1016/j.ijcard.2006.07.013.

Watt, S., Aesch, B., Lanotte, P., Tranquart, F., \& Quentin, R. (2003). Viral and bacterial DNA in carotid atherosclerotic lesions. Eur $J$ Clin Microbiol Infect Dis, 3, 99-105. http://dx.doi.org/10.1007/s10096-002-0867-1.

West, S. K., Kohlhepp, S. J., Jin, R., Gleaves, C. A., Stamm, W., \&Gilbert, D. N. (2009). Detection of circulating Chlamydophila pneumoniae in patients with coronary artery disease and healthy control subjects. Clin Infect, 48, 560-567. http://dx.doi.org/10.1086/596710.

Wohlschlaeger, J., Wimmer, M. L., Nogler, D. K., Haberl, R., \& Weis, S. (2005). Identification of Chlamydia pneumoniae in intracranial and extracranial arteries in patients with stroke and in controls: combined immunohistochemical and polymerase chain reaction analyses. Hum Pathol, 36, 395-402. http://dx.doi.org/10.1016/j.humpath.2005.02.003.

Woods, G. L., Walker, D. H., McPherson, R. A., \& Pincus, M. R. (2007). Henry's Clinical Diagnosis and Management by Laboratory Methods, 21st ed. Pennsylvania: Elsevier Saunders.

Zibaeenezhad, M. J., Amanat, A., Alborzi, A., \& Obudi, A. (2005). Relation of Chlamydia pneumoniae infection to documented coronary artery disease in Shiraz, Southern Iran. Angiology, 56, 43-48. http://dx.doi.org/ $10.1177 / 000331970505600106$

\section{Copyrights}

Copyright for this article is retained by the author(s), with first publication rights granted to the journal.

This is an open-access article distributed under the terms and conditions of the Creative Commons Attribution license (http://creativecommons.org/licenses/by/3.0/). 